\title{
MAKNA SYAIR MADIHIN BAINTAN KEBUDAYAAN BANJARMASIN MENGGUNAKAN PENDEKATAN STRUKTURALISME
}

oleh

\author{
Achmad Muhlisin \\ Alifiana Izha Gandhi \\ Safira Nur Arfiani \\ Achmadmuhlisin49@gmail.com \\ Alifianaizha14@gmail.com \\ savierraarfiany@gmail.com
}

\begin{abstract}
ABSTRAK
Penelitian dengan judul "Makna Syair madihin Baintan Kebudayaan Banjarmasin Menggunakan Pendekatan Struktural”. Tujuan dari penelitian ini adalah untuk mengetahui makna denotasi dan konotasinya. Teori yang digunakan ialah teori Roland Barthes dengan pendekatan struktural. Metode yang digunakan dalam penelitian ini adalah metode jenis penelitian kualitatif yang mengkaji berupa kalimat dan bukan berupa angka. Sumber data yang diambil adalah Video Baintan Baintan karya Gozali Rahman. Teknik pengumpulan data yaitu melalui rekaman dan wawancara. Dari hasil penelitian diperoleh simpulan bahwa kesenian tradisional Baintan terdapat makna konotasi dan denotasi. Makna Konotasi dari Baintan Baintan tersebut yakni terjemahan bahasa Indonesia yang belum dimaknai sedangkan makna denotasi dari Baintan Baintan tersebut yakni terdapat makna gurauan dan makna budaya yang memiliki makna sebagai kegiatan hiburan juga makna untuk memperkenalkan identitas daerah pemadihin.
\end{abstract}

\section{Kata Kunci : Baintan, Makna, Konotasi \& Denotasi}

\section{ABSTRAC}

The research aims to conserve the culture Baintan with point of view the element inside the lyric of Baintan Baintan and then to know how mean connotation and denotation.The research using Roland Barthes theory is Focused in to the meaning of 
FON ; Jurnal Pendidikan Bahasa dan Sastra Indonesia

Volume 13 Nomor 2 Tahun 2018

the sentence and using Structural approach. The research use qualitative method, qualitative method reviewing that sentence not the numbers. The data source obtained video Baintan Baintan by Gozali Rahman. Techniques collecting data using recording and interview techniques. The Conclusion of this research is Baintan Baintan have a mean denotation and connotation. Mean of connotation from Baintan Baintan like a translate lyric from banjar language to Indonesian language. While denotation mean from Baintan Baintan have a mean joke and mean cultural, which as action of entertainment and to introduce his culture identity.

\section{Key word : Baintan, Mean, Connotation \& denotation}

\section{PENDAHULUAN}

Kebudayaan daerah merupakan kekayaan berharga yang dimiliki oleh negara tersebut. Budaya merupakan suatu cara hidup yang berkembang dan dimiliki bersama oleh sebuah sekelompok orang dan diwariskan dari generasi ke generasi (Eki, 2014:263). Kebudayaan daerah tersebut dapat menjadikan suatu negara bisa dikenal oleh siapapun, dengan salah satu alasannya kebudayaan tersebut tidak punah dan banyak peminatnya. Begitu pula dengan daerah Kalimantan khususnya Kalimantan Selatan yang notabenenya semua masyarakat di sana adalah suku Dayak Ngaju dan Dayak Sungai. Mereka masih mempercayai adanya tradisi-tradisi yang sangat kental dengan kepercayaan nenek moyang. Kalimantan Selatan yang disebutkan meliputi Banjarmasin, Martapura, dan Barabai. Di daerah tersebut mayoritas memegang erat budaya Islam dan beragama Islam, bahkan Islam masuk di Indonesia melalui Banjarmasin terlebih dahulu. Cara agama Islam masuk ke Kalimantan Selatan adalah dengan salah satu budaya yang sangat menarik berupa kesenian Baintan.

Pada zaman modern saat ini, peminat kesenian Baintan ini semakin sedikit. Kejelasan itu makin terlihat ketika banyak peBaintan dalam pertunjukan sudah berumur tua. Kesenian Baintan pada tahun 2014 lalu, telah ditetapkan oleh UNESCO sebagai Warisan Budaya Tak Benda milik Indonesia yang berasal dari Kalimantan Selatan. Namun dalam kenyataannya keberadaan kesenian Baintan pada saat ini tidak harmoni dengan pengakuan UNESCO tersebut, kesenian Baintan kurang mendapatkan minat dari generasi muda, hanya sedikit yang berminat untuk mempelajari dan 
FON ; Jurnal Pendidikan Bahasa dan Sastra Indonesia

Volume 13 Nomor 2 Tahun 2018

melestarikan kesenian ini (Sani, 2017:81).

Oleh karena itu, tulisan ini akan membahas tentang bagaimana makna konotatif dan denotative pada syair madihin Baintan .

Seperti yang telah dijelaskan di atas, Penelitan ini memiliki konteks pembahasan mengenai makna yang terdapat dalam syair Baintan. Selain itu penelitian ini juga membahas tentang kaum muda yang telah melupakan kesenian Baintan ini. Baintan adalah sebuah kesenian yang mendapatkan campuran budaya Islam dan dikolaborasikan dengan bahasa Banjar. Kesenian Baintan ini merupakan salah satu jenis tradisi puisi lisan yang dalam pergelarannya menggunakan musik dengan instrumen gendang. Sastra lisan merupakan semua cerita yang sejak awalnya disampaikan secara lisan, tidak ada naskah tertulis yang dapat dijadikan pegangan (Zaimar,2008 dalam Yahya, 2017:164). Keberadaan tradisi lisan itu umumnya semakin dipengaruhi oleh tuntutan praktis-pragmatis untuk memenuhi kebtuhan-kebutuhan pokoknya (Sedyawati, 2008:7-8). Pendapat lain mengatakan bahwa Baintan juga berasal dari bahasa Banjar, yaitu papadah atau mamadahi atau dalam Bahasa Indonesia berarti memberikan nasihat (Rafiek,
2012:106). sedangkan menurut Turner (Murgianto, 2008:14-15) tradisi lisan yang dikaitakan dengan pertunjukan dan menghubungkan pengalaman, pragmatis, praktis, dan pertunjukan.

Kesenian Baintan ini biasa digunakan oleh masyarakat pemadihin (Orang yang melantunkan Syair madihin) untuk meluapkan kritikan kepada pemerintahan, kritikan itu berupa sindiran, selain itu Baintan ini juga bahan hiburan masyarakat Banjarmasin, karena syairsyair Baintan tersebut biasanya mengandung unsur humor. Unsur lainnya yang terdapat dalam Baintan menurut Hasuna (2017:41) ada beberapa unsur di antaranya unsur pendidikan, unsur moral, unsur agama dan lain-lain.

Objek yang akan dibahas dalam penelitian ini ialah syair Baintan dengan judul "Baintan" yang di syairkan oleh Pemadihin Banjarmasin yaitu Gazali Rahman. Secara Garis besar kandungan dari lirik Baintan ini berkisah mengenai kesenian yang ada di Banjarmasin dan nasihat dalam menunaikan ibadah puasa Ramadhan. Menurut Gazali Rahman, Baintan ini dipergunakan untuk memperkenalkan kebudayaan yang ada di Banjarmasin dan juga sebagai cara mengingatkan orang dalam menunaikan 
FON ; Jurnal Pendidikan Bahasa dan Sastra Indonesia

Volume 13 Nomor 2 Tahun 2018

ibadah Ramadhan. Masalah yang di kaji dalam tulisan ini adalah dengan menggali makna yang terdapat dalam lirik Baintan dengan teori semiotik, bahwa penyair membuat lirik tersebut dengan tujuan untuk mengungkit makna apa yang terkandung dalam sastra lisan tersebut makna konotatif dan denotatif.

Penelitian syair Baintan ini sudah banyak diteliti, namun pada Baintan dengan judul Baintan ini belum pernah diteliti. Syair Baintan yang banyak diteliti umumnya menjelaskan tentang dampak Baintan, hingga penerapan Baintan sebagai membentuk karakter anak-anak. Penelitian ini memiliki defisiensi terhadap penelitian yang lain, yaitu terhadap materi yang diteliti dan objek penelitiannya. Penelitian ini bertujuan untuk mengetahui makna konotatif dan denotatif dari syair Baintan. Hal ini diperkuat oleh banyaknya anak muda yang tidak tau Baintan tersebut, bahkan ada segelintir anak muda yang tidak mengetahui kesenian ini. Oleh karena itu penelitian ini sangat penting dilakukan untuk melestarikan dan bisa menjadi alat atau sarana bagi masyarakat setempat agar bisa menikmati kebudayaan ini dari semua golongan. Bahasa yang digunakan merupakan bahasa daerah dari Banjarmasin, jika bahasa tersebut punah maka pemuda-pemuda atau anak cucu kita nantinya tidak akan tahu makna bahasa tersebut. Seperti yang telah diutarakan oleh Ruswanto (2014:31) yaitu bahasa memiliki fungsi sebagai media transmisi (sosialisasi) unsur-unsur kebudayaan dari satu generasi kepada generasi berikutnya. Karena fungsinya itu, bahasa menjadi salah satu unsur penting untuk dipelajari oleh semiotik. Teori yang digunakan dalam pengkajian ini menggunakan teori Roland Barthes dengan meneliti makna denotatif dan konotatif dalam Baintan tersebut.

\section{KAJIAN PUSTAKA}

Pada pendahuluan, peneliti telah menyinggung mengenai pendekatan yang digunakan dalam mengkaji sastra lisan dengan judul Baintan ini. Peneliti menggunakan pendekatan strukturalisme. Pendekatan yang digunakan dalam penelitian ini menggunakan teori semiotik Roland Barthes. Semiotik adalah suatu metode analisis yang mengkaji tentang tanda-tanda. Asumsi Roland Barthes bahwa dalam teks setidaknya memiliki lima kode sebagai suatu sistem makna luar yang lengkap sebagai acuan dari setiap tanda, menurut Barthes terdiri atas lima jenis kode, yaitu (1) kode hermeneutik (kode teka-teki), (2) kode semik (makna 
konotatif), (3) kode simbolik, (4) kode laten (denotatif) dan isi komunikasi proaretik (logika tindakan), (5) kode (konotatif), sedangkan menurut Roland gnomik (kode kultural), (Lustyantie Barthes sendiri Dalam teorinya, Barthes 2012:6). Kode hermeneutik merupakan menggunakan tiga hal yang menjadi inti simbol harapan pembaca untuk dalam penelitiannya, yakni makna mendapatkan "kebenaran" bagi denotatif, konotatif dan mitos pertanyaan yang muncul dalam teks. Kode (Mahadian,2015:998).Oleh karena itu teka-teki merupakan unsur terstruktur pendekatan ini cocok untuk mengkaji yang utama dalam narasi tradisional. sastra lisan ini, karena banyak hal penting Sedangkan yang dimaksud kode semik yang dapat diketahui oleh pendengar adalah kode yang memanfaatkan isyarat, melalui pertunjukan Baintan tersebut petunjuk, atau "kilasan makna” yang selain itu sama dengan tujuan penelitian ditimbulkan oleh penanda-penanda ini yaitu untuk mengetahui makna kootatif tertentu. Kode ketiga adalah kode dan denotatif. simbolik merupakan kode “pengelompokan” atau konfigurasi. Kode selanjutnya yaitu kode proaretik atau kode tindakan dianggapnya sebagai perlengkapan utama teks yang dibaca orang. kode gnomik atau kode kultural banyak jumlahnya. Kode ini merupakan acuan teks ke benda-benda yang sudah diketahui dan dikodifikasi oleh budaya.

Pendekatan strukturalisme dengan teori Roland Barthes ini cocok dan membantu dalam proses pengkajian karena terkait dengan Baintan tersebut sangat tepat dalam menjelaskan isi kandungan makna konotatif dan denotatif dalam Baintan tersebut. Pendekatan ini cocok untuk diterapkan dalam penelitian ini karena pada syair Baintan terdapat isi

\section{METODE PENELITIAN}

Madihin yang berjudul Baintan ini ditulis oleh pengarang untuk mengkritik atau di dalamnya berisi sindiran untuk para petinggi-petinggi hingga untuk hiburan dari masyarakat Banjarmasin. Jenis penelitian yang digunakan adalah metode kualitatif. Dalam penelitian kualitatif data yang digunakan berupa kalimat dan bukan berupa angka.

Pendekatan yang digunakan dalam penelitian ini menggunakan teori struktural Roland Barthes. pendekatan ini dirasa cocok untuk diterapkan dalam penelitian ini karena Pada syair Baintan terdapat isi laten (denotatif) dan isi 
FON ; Jurnal Pendidikan Bahasa dan Sastra Indonesia Volume 13 Nomor 2 Tahun 2018

komunikasi (konotatif), sedangkan untuk meneliti gaya tulisan seorang menurut Roland Barthes sendiri Dalam pengarang. Analisis isi adalah metode teorinya, Barthes menggunakan tiga hal ilmiah untuk mempelajari dan menarik yang menjadi inti dalam penelitiannya, kesimpulan atas suatu fenomena, dengan yakni makna denotatif, konotatif dan memanfaatkan dokumen pada isi media mitos. (Mahadian,2015:998)

Sumber data Sumber data penelitian cetak maupun elektronik. Lewat analisis isi, peneliti dapat mempelajari gambaran ini yakni syair madihin yang berjudul isi, karakteristik pesan, dan perkembangan "Baintan” yang merupakan kesenian daerah Kalimantan Selatan, khususnya daerah Martapura, Banjarmasin, dan Barabai. Data yang digunakan adalah isi syair Baintan yang berjudul "Baintan" dengan pemadihin Gazali Rahman yang merupakan pemadihin asli dari Kalimantan Selatan, Gazali Rahman juga dibantu oleh temannya yaitu Bagus yang juga pemadihin berasal dari Kalimantan Selatan.

Penelitian ini menggunakan metode analisis isi. Analisis isi digunakan karena berfokus pada isi komunikasi suatu teks. Menurut Rakhmat (dalam Fitri, 2011:28) analisis isi adalah analisis yang digunakan untuk menganalisis semua bentuk komunikasi yaitu berupa surat kabar, dengan menggunakan handphone dan buku, puisi, lagu, cerita rakyat, lukisan, laptop. Teknik analisis data yang pidato, surat, peraturan, undang-undang, digunakan peneliti adalah (1) peneliti akan musik, teater, dan lain sebagainya. mencatat syair yang diucapkan oleh

Metode analisis isi ini untuk mengetahui arti dan makna yang ada pada syair Baintan. Metode ini digunakan juga peBaintan pada video, (2) kemudian syair tersebut akan di terjemahkan kedalam bahasa Indonesia agar mempermudah 
dalam menganalisis isi syair Baintan tersebut, dan tahap selanjutnya adalah (3) pemaknaan atau analisis makna yang terdapat pada syair Baintan menurut konteks makna konotatif dan denotatif. Pengecekan keabsahan data menurut Yusuf (2014), melalui uji kredibilitas, uji transferabilitas, uji dependipilitas dan uji komformabilitas.

\section{HASIL DAN PEMBAHASAN}

\section{A. Makna Denotatif}

Kesenian Baintan dengan judul Baintan ini digunakan oleh masyarakat Kalimantan Selatan khusunya daerah Martapura, Banjarmasin, Barabai telah memakai kesenian Baintan ini sejak dulu pada kerajaan-kerajaan Islam sebagai bentuk pengkritikan terhadap pemimpin yang pada saat itu memimpin kerajaan Banjar. Selain itu kesenian ini juga dipakai untuk bahan hiburan dan sindiran pada acara-acara daerah dengan penyair yang disebut dengan pemadihin. Pemadihin adalah orang yang melantunkan syair Baintan tersebut. Biasanya pemadihin tersebut adalah orang-orang penting seperti tokoh masyarakat, pemuka agama, dan sastrawan-sastrawan di daerah tersebut.
Makna pada syair Baintan yang dilantunkan umumnya beragam tergantung pada situasi acara daerah tersebut. Jika acara tersebut mengenai pernikahan, maka peBaintan harus menyiapkan syair atau lirik yang berhubungan dengan pernikahan, dan jika acara tersebut mengenai acara keagamaan maka syair Baintan yang di lantunkan berupa pesan moral dan nilai-nilai agama yang berlaku di daerah tersebut.

Struktur Baintan sendiri yaitu seperti berikut (1) Pembukaan, dengan menyanyikan sampiran sebuah pantun yang diawali dengan pukulan tarbang yang disebut pukulan membuka. Pada sampiran ini biasanya menyangkut tema yang akan dibawakan peBaintan. (2) Memasang tabi, yakni membawakan syair-syair atau pantun yang isinya menghormati penonton, memberikan pengantar, terima kasih atau permohonan maaf jika nanti ada salah kata dalam membawakan Baintan. Menyampaikan isi (manguran), yaitu menyampaikan syair atau pantun yang isinya sesuai dengan tema acara atau permintaan panitia. Sebelum isi dari tema Baintan dikupas oleh paBaintanan, sampiran pantun di awal 
FON ; Jurnal Pendidikan Bahasa dan Sastra Indonesia Volume 13 Nomor 2 Tahun 2018

harus disampaikan isinya terlebih yang berjudul "Baintan”. Secara garis dahulu (mamacah bunga). (4) besar Baintan "Baintan” ini Penutup, yakni menyampaikan menjelaskan tentang nilai-nilai agama kesimpulan, sambil menghormati pada bulan Ramadhan, dan juga penonton, mohon pamit, dan ditutup menjelaskan tentang Kebudayaan dan dengan pantun penutup.

Pada kajian ini syair Baintan yang digunakan ialah syair Baintan makanan khas daerah Banjarmasin tersebut. Berikut lirik Baintan dengan judul Baintan :

\begin{tabular}{|c|c|c|}
\hline No & Lirik Asli & Makna Literal \\
\hline & $\begin{array}{l}\text { martapura bagalar kuta sarambi } \\
\text { makkah (Pembukaan } \\
\text { asalamualaikum warohmatullah } \\
\text { waalaikumsalam warohmatullah } \\
\text { salamat ramadhan bulan nang } \\
\text { penuh barkah manyaksikan } \\
\text { salamat panuntun nang } \\
\text { baBaintan } \\
\text { dirumah } \\
\text { banyak urangnya disana cantik wan } \\
\text { gagah }\end{array}$ & $\begin{array}{l}\text { martapura bagalar kota sarambi } \\
\text { makkah (Pembukaan) } \\
\text { asalamualaikum warohmatullah } \\
\text { waalaikumsalam warohmatullah } \\
\text { salamat ramadhan bulan yang penuh } \\
\text { barkah } \\
\text { salamat manyaksikan kami baBaintan } \\
\text { penonton dirumah } \\
\text { disana orangnya banyak yang cantik } \\
\text { dan ganteng } \\
\text { ada yang berbadan tinggi dan ada yang }\end{array}$ \\
\hline
\end{tabular}




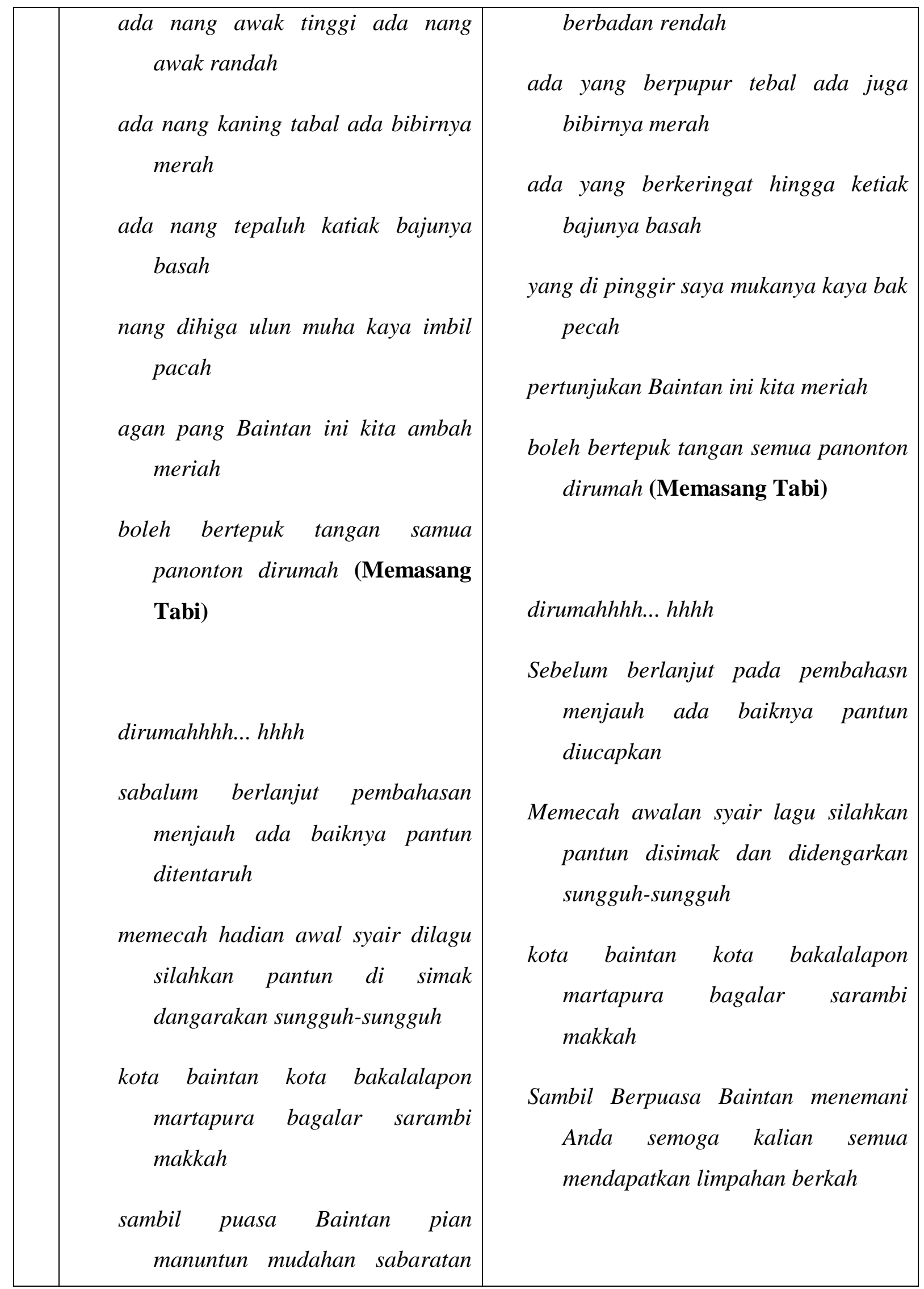




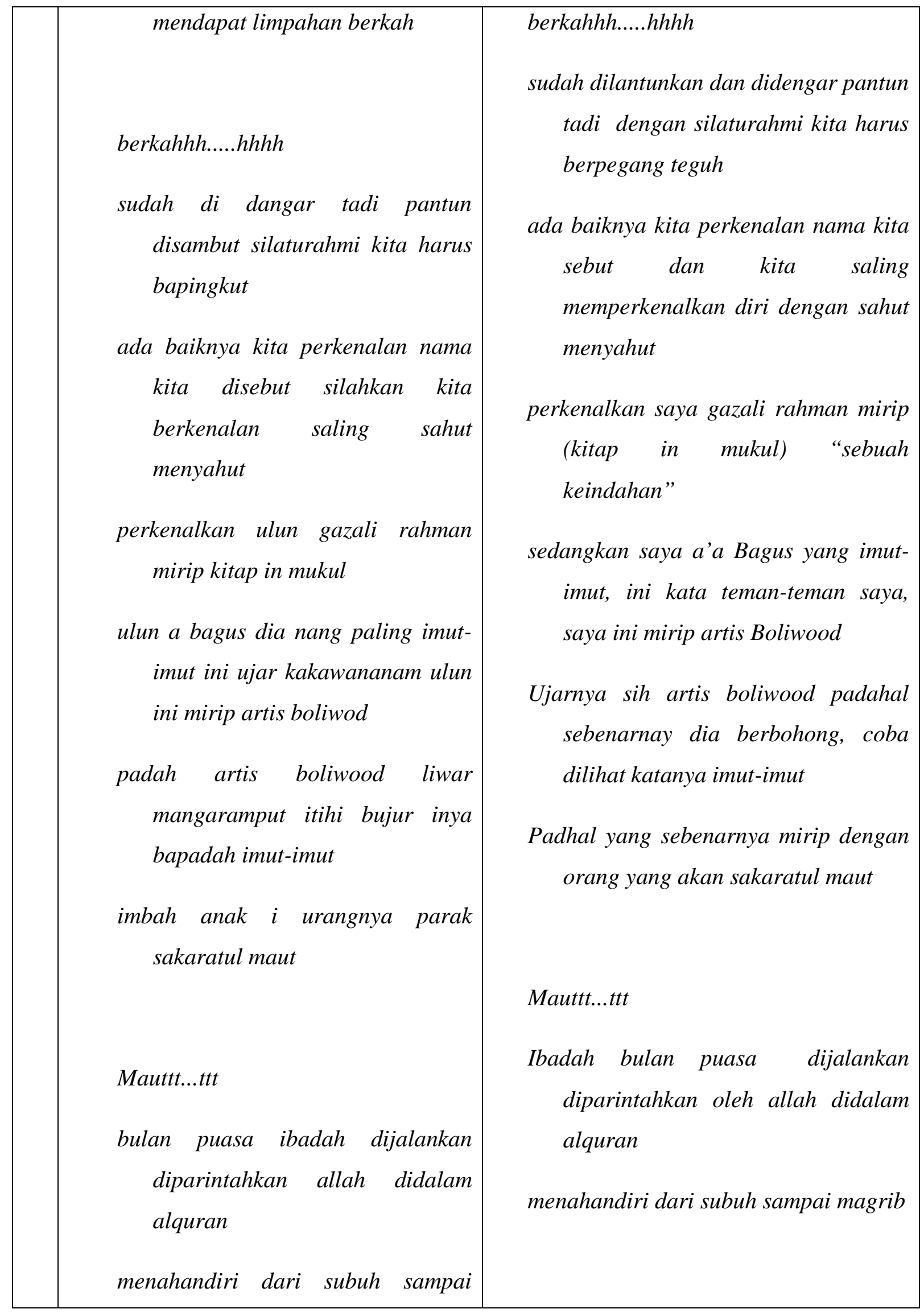


FON ; Jurnal Pendidikan Bahasa dan Sastra Indonesia Volume 13 Nomor 2 Tahun 2018

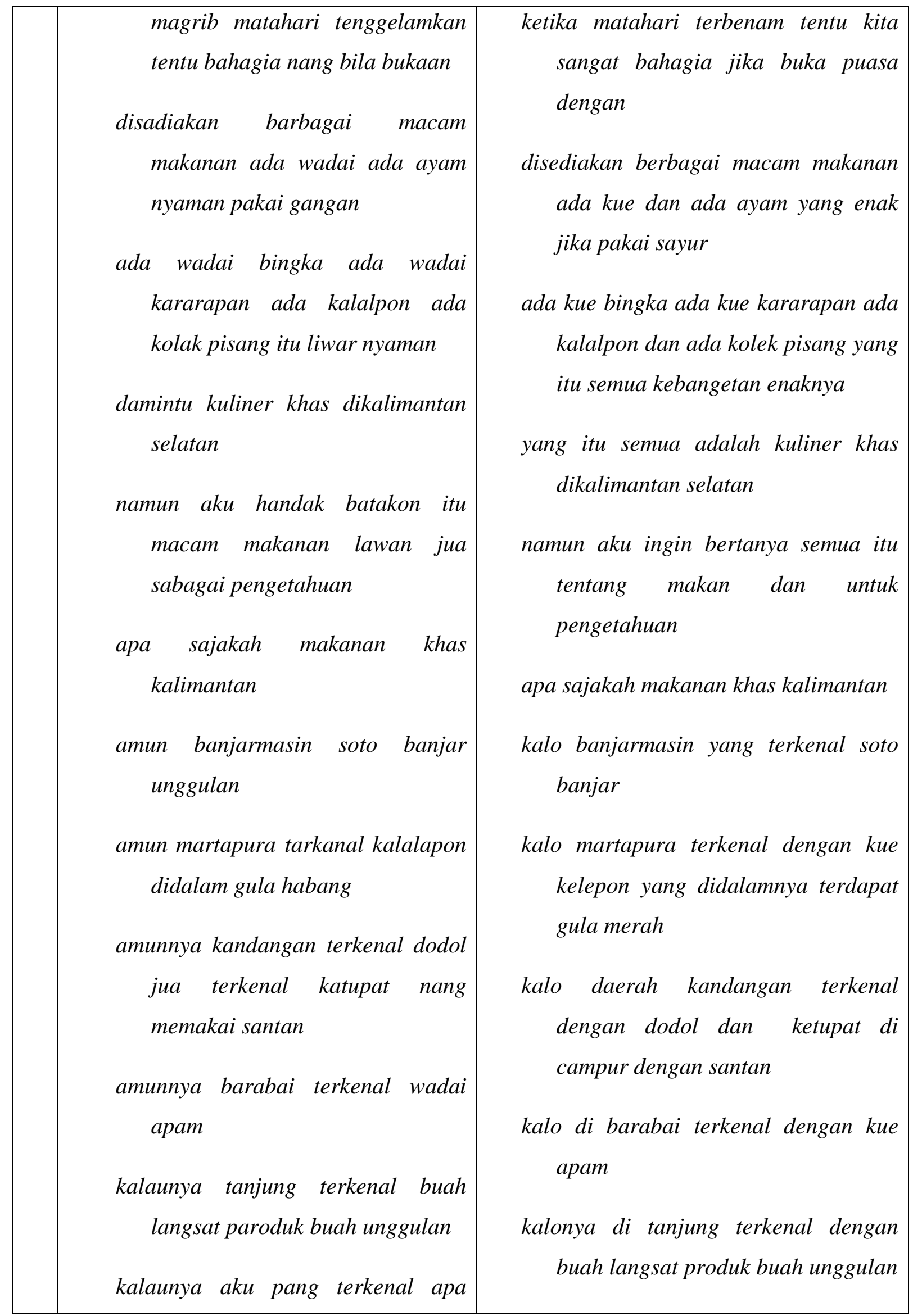


FON ; Jurnal Pendidikan Bahasa dan Sastra Indonesia Volume 13 Nomor 2 Tahun 2018

\begin{tabular}{|c|c|}
\hline silah kan ikam sebutkan & $\begin{array}{c}\text { kalo aku terkenal apanya sih silahkan } \\
\text { kalaunya ikam terkenal liur }\end{array}$ \\
baungat(Pesan/Isi) & kalonya kamu terkenal dengan liuryang \\
menggantung dan menetes(Pesan / \\
hiiii...iii awan barsatu langsung batahan \\
aaaa...aaaa(penutup) \\
isi) \\
\\
\\
\end{tabular}

Syair Baintan diatas merupakan pembahasan sendiri-sendiri. Dalam Syair dalam bentuk bahasa tradisional kutipan Baintan diatas terdapat 3 nilai Banjar, dengan campuran bahasa halus yang menjadi ciri khas Baintan ini yaitu dan kasar di daerah tersebut. Syair (1) terdapat unsur candaan yang terlihat Baintan tersebut ditulis oleh Gajali pada bagian Memasang tabi yaitu Rahman yaitu peBaintan yang merupakan membawakan syair-syair atau pantun yang penduduk asli dari kota Banjarmasin isinya menghormati penonton, Kalimantan Selatan. Dalam Baintan memberikan pengantar, terima kasih atau tersebut terdapat dua orang yang permohonan maaf jika nanti ada salah kata melantunkan syairnya, agar mereka dapat dalam membawakan Baintan, selain itu di bersahut-sahutan dan sebagai bagian dari dalam isi bait ke 2 juga itu merupakan strategi untuk mendapatkan kelucuan unsur candaan. (2) terdapat unsur budaya dengan meledek antar peBaintan. Dalam yang terlihat dari bait terakhir pesan/ isi Baintan yang berjudul baintan tersebut yang menjelaskan macam-macam memiliki arti sebagai berikut dalam : $\quad$ kmakanan khas Banjarmasin. (3) terdapat Baintan diatas terdapat 4 bait yang unsur religi yang terlihat dari bait ke 3 mana setiap bait memiliki point pada pesan /isi selain itu terdapat pula lirik yang menyinggung tentang bulan 
FON ; Jurnal Pendidikan Bahasa dan Sastra Indonesia

Volume 13 Nomor 2 Tahun 2018

Ramadhan ini pada larik kedua dari poin

yang memang menjadikan pokok memasang Tabi

\section{B. Makna Konotatif}

\section{Makna Gurauan}

Pada proses pemaknaan ini pembahasan yaitu hanya pada bagian membuka tabi dan pesan/isi. Pertama yaitu dari lirik berikut:

peneliti menggunakan kutipan

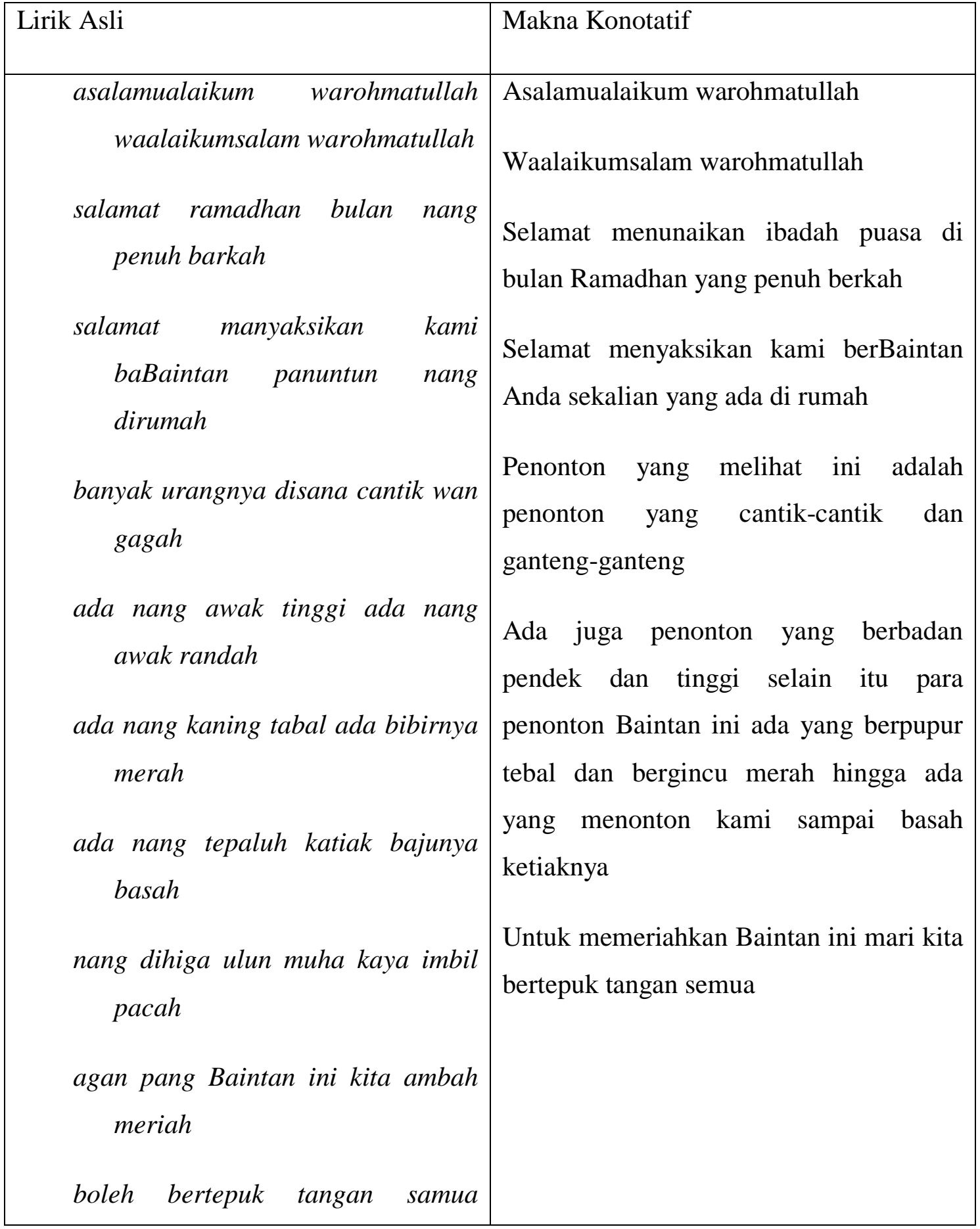




\begin{tabular}{|c|c|}
\hline $\begin{array}{l}\text { panonton dirumah (Memasang } \\
\text { Tabi) }\end{array}$ & \\
\hline $\begin{array}{l}\text { perkenalkan ulun gazali rahman } \\
\text { mirip kitap in mukul } \\
\text { ulun a bagus dia nang paling imut- } \\
\text { imut ini ujar kakawananam ulun } \\
\text { ini mirip artis boliwod } \\
\text { padah artis boliwood liwar } \\
\text { mangaramput itihi bujur inya } \\
\text { bapadah imut-imut } \\
\text { imbah anak i urangnya parak } \\
\text { sakaratul maut }\end{array}$ & $\begin{array}{l}\text { Perkenalkan saya Gazali Rahman yang } \\
\text { mirip sebuah keindahan layaknya kitap } \\
\text { suci } \\
\text { Sedangkan saya adalah abang Bagus } \\
\text { yang paling imut, kata teman saya saya } \\
\text { ini mirip artis Boliwood, } \\
\text { Mimpi seperti artis bolowood padahal ia } \\
\text { berbohong lihat saja orang nya seperti } \\
\text { dekat dengan waktunya sakratul maut }\end{array}$ \\
\hline
\end{tabular}

Dilihat dari terjemahan lirik Baintan tersebut dapat disimpulkan bahwa peBaintan menggunakan pengumpamaan dalam menyanjung pendengar atau penonton dengan sebutan ganteng dan cantik. Hal ini muncul karena adanya tujuan tersendiri dalam komunikasi tersebut seperti halnya yang di utarakan oleh Faridah (2017:92) Tuturan humor timbul karena ada dua orang atau lebih yang sedang melakukan komunikasi di dalam tuturan tersebut mengandung maksud, tujuan dan fungsi pragmatik tertentu dan menghasilkan beberapa pengaruh pada lingkungan penyimak.

Pada lirik yang di pinggir saya mukanya kaya bak pecah pemadihin pembuka memberikan sindiran kepada lawan pemadihin kedua dengan candaan yang mengarah pada fisik lawan pemadihinnya dalam lirik tersebut bermakna bahwa orang yang berada disamping peBaintan 
tersebut memiliki muka seperti bak pecah .

Lirik lainnya seperti ada yang berpupur tebal ada juga bibirnya merah.......ada yang berkeringat hingga ketiak bajunya basah. Lirik tersebut memiliki makana bahwa pemirsa yang menonton Baintan tersebut ada yang berlebihan dalam berpenampilan, dan lirik selanjutnya menjelaskan bahwa ada yang menonton Baintan dengan penampilan yang sederhana dan tidak memikirkan kesopanan, karena melihat Baintan hingga ketiaknya basah.

\section{Makna Budaya}

Baintan Baintan tersebut memiliki unsur budaya yang ingin diperkenalkan pemadihin untuk pendengar. Unsur budaya tersebut disisipkan oleh pemadihin dengan cara menghubungkan dengan bulan Ramadhan yang dimana identik dengan makanan-makanan enak, oleh karena itu pemadihin langsung menghubungkan dengan makanan khas Banjarmasin yang disisipkan dengan tujuan untuk memperkenalkan makanan daerah. Lirik tersebut dapat dilihat pada kutipan berikut:

\begin{tabular}{|r|l|}
\hline Lirik Asli & Makna Konotatif \\
\hline $\begin{array}{r}\text { bulan puasa ibadah dijalankan } \\
\text { diparintahkan allah didalam al-quran }\end{array}$ & $\begin{array}{l}\text { Di dalam al-quran di perintahkan } \\
\text { untuk menjalankan ibadah puasa } \\
\text { pada bulan ramadhan dengan }\end{array}$ \\
menahandiri dari subuh sampai magrib & menahan hawa nafsu dari terbit fajar \\
matahari tenggelamkan tentu bahagia & hingga tenggelamnya matahari \\
nang bila bukaan & saat berbuka puasa kita sangat \\
disadiakan barbagai macam makanan & senang, karena terdapat makanan \\
ada wadai ada ayam nyaman pakai & khas Kalimantan selatan seperti jika \\
gangan didaerah banjarmasin kita akan \\
ada wadai bingka ada wadai kararapan \\
ada kalalpon ada kolak pisang itu \\
liwar nyaman
\end{tabular}


FON ; Jurnal Pendidikan Bahasa dan Sastra Indonesia Volume 13 Nomor 2 Tahun 2018

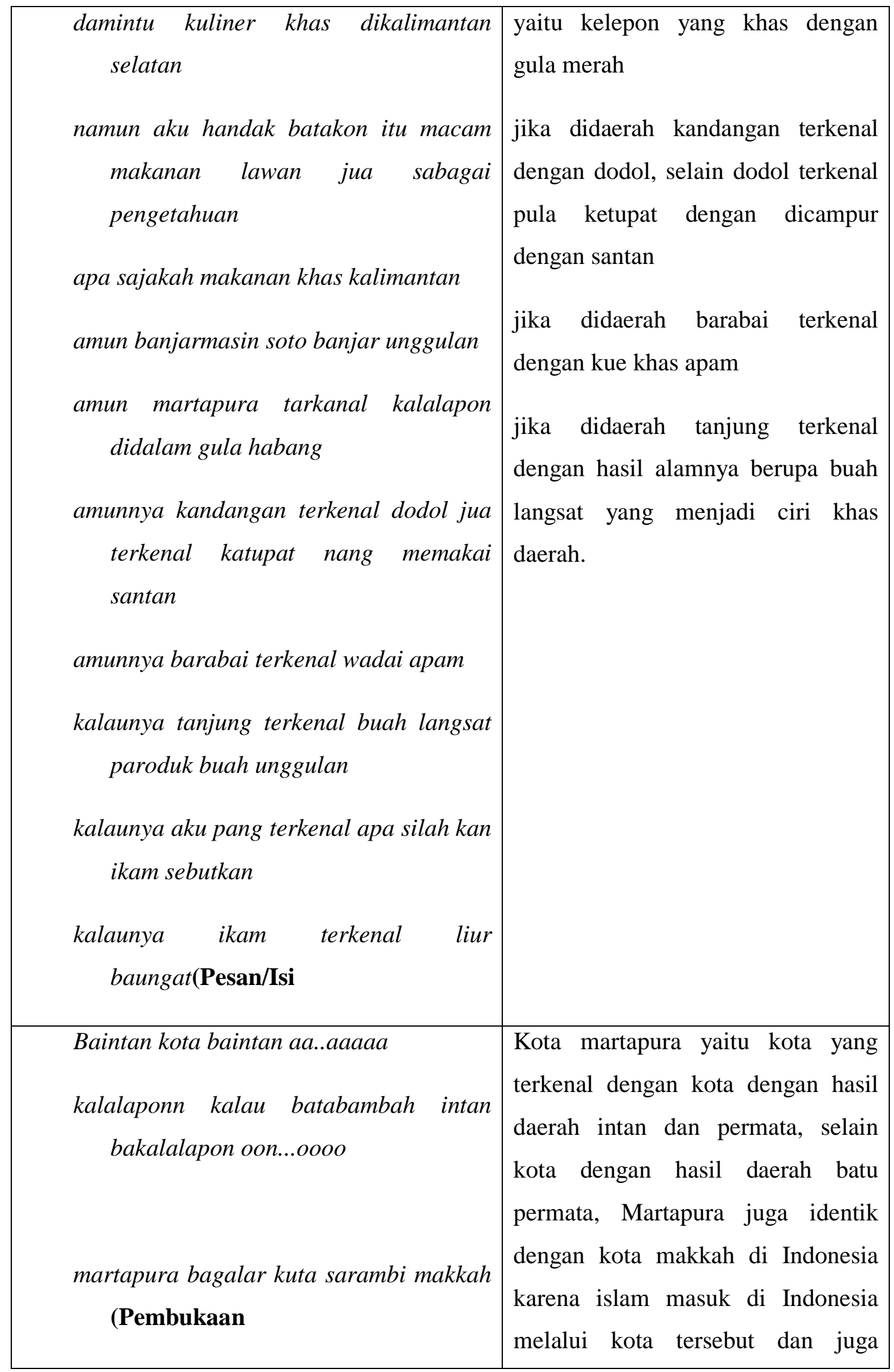




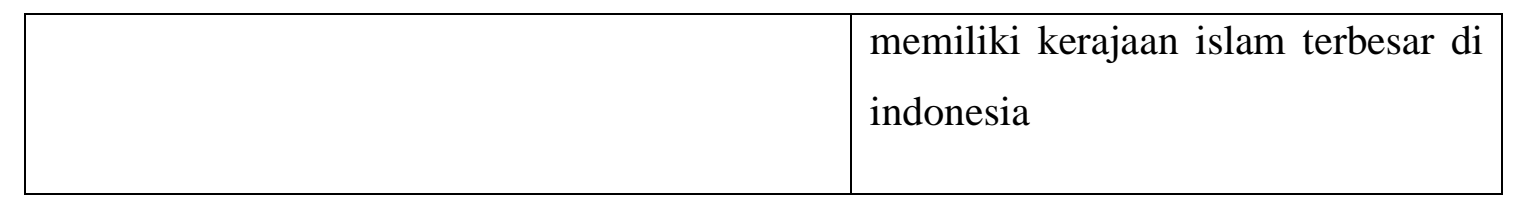

Selain itu terlihat dari larik terakhir peBaintan memberikan unsur candaan lagi agar mereka ttidak memperlihatkan kalau mereka sedang mempromosikan makanan khas daerah mereka. Cara penyair melantunkan dan memperkenalkan makanan khas daerahnya dengan cara bertanya jawab yang seolah-olah peBaintan kedua tidak mengetahui apa makanan khas Kalimantan Selatan. Penjelasan itu dapat terlihat pada kutipan berikut:

“namun aku handak batakon itu macam makanan lawan jua sabagai pengetahuan” “Namun aku mau bertanya macam-macam Makanan sebagai pengetahuan.”

Dari kutipan diatas dapat dilihat bahwa pemadihin kedua bertanya pada pemadihin pertama bahwa apa sajakah makanan khas Kalimantan Selatan. Begitulah cara penyair memperkenalkan makanan khas daerahnya untuk dikenal oleh orang yang bukan berasal dari Kalimantan Selatan. Dengan begitu penyampaian makana unsur budaya tidak terlepas dengan kesenian mereka.

\section{KESIMPULAN}

Pada dasarnya semiotik merupakan kajian pada karya sastra yang memfokuskan pada makna penutur yang disesuaikan dengan konteksnya sehingga memungkinkan untuk lebih mengaetahui apa yang dikomunikasikan daripada yang dikatakan. Secara garis besar Baintan “Baintan” ini menjelaskan tentang nilainilai agama pada bulan Ramadhan, dan juga menjelaskan tentang Kebudayaan dan makanan khas daerah Banjarmasin.

Syair Baintan Banjar mempunyai nilai-nilai luhur di dalamnya dan bisa dimaanfaatkan guna untuk menciptakan sastra lisan daerah. Pelestarian sastra lisan sangat penting dilakukan, karena sastra lisan hanya diingat oleh kalangan usia tua atau sesepuh yang semakin lama makin berkurang. Syair Baintan ini juga bisa dimanfaatkan sebagai penunjang perkembangan sastra lisan yang ada di setiap daerah dan syair Baintan ini juga mengungkapkan pikiran-pikiran, sikap dan norma-norma yang ada pada 
FON ; Jurnal Pendidikan Bahasa dan Sastra Indonesia

Volume 13 Nomor 2 Tahun 2018

masyarakat tersebut. Tidak hanya itu sastra lisan juga berguna terhadap kebudayaan karena bahasa dapat dijadikan sebagai media, untuk mempererat ikatannya dengan kemajuan bahasa masyarakat pendukungnya, supaya syair Baintan ini tidak mengalami kepunahan akibat kalangan muda yang tidak mengetahui dan melestarikan kesenian daerahnya, untuk itu harus diadakan pelestarian kepada generasi ke generasi agar mereka dapat mengenal serta menikmati kekayaan budaya lisan di daerahnya.

Pada syair Baintan setelah dilakukan analisis dengan menggunakan teori Semiotik Roland Barthes ditemukannya dua unsur pokok makna yang terkandung yaitu makna konotatif dan denotatif. Makna konotatif pada syair tersebut yaitu terjemahan dari bahasa Banjarmasin ke bahasa Indonesia yang terjemahan tersebut bukan dari maknanya melainkan dari struktur kata dan kalimatnya. Makna denotatif dari Baintan tersebut ialah makna tersirat atau makna sebenarnya yang ada dalam syair tersebut. Dalam makna denotaf terdapat dua unsur makna yaitu makna budaya dan makna Gurauan, dimana dalam lirik syair gurauan memiliki makna menyindir penonton yang hadir dengan candaan fisik dengan pengibaratan “jelek" selain itu terdapat pula makna syair budaya yang menjelaskan bahwa mereka seolah-olah tidak mengetahui makanan khas daerah dengan bertanya pada satu sama lain dengan maksud untuk memberitahukan kepada penonton bahwa mereka memilki makanan khas daerah seperti kelepon, lontong sayur, apam Barabai dan sebagainya.

\section{DAFTAR PUSTAKA}

Almunaware, Almaidah ,dkk.2015.

Analisis Isi Berita Kontroversi

Basuki Tjahaja Purnama Dalam

Konteks Pengangkatan Gubernur

Dki Jakarta Pada Surat Kabar

Tribun Manado. Acta Diurna. 4(3)

Eki, R. 2013. "Upaya Majalah

Emusikaltim Dalam Meningkatkan

Kepedulian Masyarakat Tentang

Kebudayaan Kaltim di Kota

Samarinda”. eJournal Ilmu

Komunikasi. Vol 2, No 2:1.

Faridah, Siti. 2017. Fungsi Pragmatis

Tuturan Humor Baintan Banjar.

Jurnal Kredo. 1(1):91-105

Fitri, Eva. 2013. Studi Analisis Isi Kekerasan Terhadap Wanita Dalam Film Indonesia Bergenre Religi Periode Tahun 2011. (Doctoral dissertation, Universitas 
FON ; Jurnal Pendidikan Bahasa dan Sastra Indonesia

Volume 13 Nomor 2 Tahun 2018

Muhammadiyah Surakarta). (Online) http://repository.ut.ac.id.

(Online) http://eprints.ums.ac.id.

diakses pada 26 Maret 2018.

diakses pada 16 April 2018.

Sani, M Budi Zakia. 2017. "Kesenian

Hasuna, Kamal., Heppy Lismayanti. 2017.

Baintan di Banjarmasin, Kalimantan

"Baintan Sebagai Kesenian

Selatan dalam tinjauan Aksiologi

Tradisional Bagi Masyarakat

dan Relevansinya terhadap

Banjar”. Lentera Jurnal Ilmiah

Pendidikan Karakter”. Journal

Kependidikan. Vol 12, No 1: 41.

Imaji. Vol 15, No 1:93.

Lustyantie, Ninuk. 2012. Pendekatan

Semiotik Model Rolan Barthes

dalam Karya Sastra Prancis.

Seminar Nasional FIB UI. UNJ.

Mahadian. A \& Ismujihastuti. 2015.

Analisis Semiotik Roland Barthes

Terhadap Sampul Album Raisa

Andriana "Raisa” dan "Heart to

Heart. E-proceeding of

Yahya, Andi Muhammad. 2017. “Kajian

Jenis, Fungsi, Dan Makna Mantra

Bugis Desa Tanjung Samalantakan

(a Study of Types, Functions, and

Meanings Buginese Mantras of

Tanjung Samalantakan

Village)”. Jurnal Bahasa, Sastra

Dan Pembelajarannya. Vol 6, No

management. Vol 2, No. 1:997-1007

2:164.

Yusuf, A. Muri. 2014. Metode Penelitian

Ruswanto, Wawan. 2014. Modul

Kuantitatif, Kualitatif, dan

Pengantar Antropologi In: Ruang

Penelitian Gabungan. Jakarta:

Lingkup Ilmu Antropologi. hlm 31.

Prenada Media Grup 